\title{
A NUMERICAL STUDY OF THE INFLUENCE OF TRANSPORT PROPERTIES OF INERT DILUENTS ON SOOT FORMATION IN A COFLOW LAMINAR ETHYLENE/AIR DIFFUSION FLAME
}

\author{
HONGSHENG GUO, ${ }^{1}$ FENGSHAN LIU, ${ }^{1}$ GREGORY J. SMALLWOOD ${ }^{1}$ AND ÖMER L. GÜLDER ${ }^{2}$ \\ ${ }^{1}$ Combustion Research Group \\ Institute for Chemical Process and Environmental Technology \\ National Research Council Canada \\ Building M-9, Montreal Road \\ Ottawa, Ontario K1A 0R6, Canada \\ ${ }^{2}$ Institute for Aerospace Studies \\ University of Toronto \\ 4925 Dufferin Street \\ Toronto, Ontario M3H 5T6, Canada
}

\begin{abstract}
The influence of transport properties of inert additives on soot formation in a coflow axisymmetric ethylene/air diffusion flame has been numerically investigated. Detailed reaction mechanism and complex thermal and transport properties were used. The fully coupled elliptic equations were solved. The radiative heat transfer from $\mathrm{CO}, \mathrm{CO}_{2}, \mathrm{H}_{2} \mathrm{O}$, and soot was calculated using the discrete-ordinates method coupled with a SNBCK-based wide-band model. A simplified two-equation soot model was used. The interactions between the soot and gas-phase chemistry were taken into account. The effects of adding argon and helium to either the fuel or the oxidant were determined.

The results show that the effects of argon and helium addition on soot formation process in a laminar ethylene/air diffusion flame are different because of the difference in their transport properties. When they are added to the fuel, argon is found to be more efficient at suppressing soot formation than helium due to the temperature difference caused by the different thermal diffusivities. However, when they are added to the coflow air, it is found that although both temperature and concentration modifications cause helium to be more efficient at suppressing soot formation than argon, it is the temperature modification that is more significant.
\end{abstract}

\section{Introduction}

Transport properties of reactants strongly affect the flame phenomena. When different inert diluents are added to the fuel or oxidant of a diffusion flame, the profiles of temperature and species concentrations, and thus the soot formation process, may be altered because of the difference in diffusivities of the diluents.

In an experimental investigation of the influence of various diluents on soot production in laminar ethylene diffusion flames, McLintock [1] found that when inert diluents were added to the oxidant, the smoke points increased in the order of argon, nitrogen, and helium. Since the heat capacities of helium and argon are same, he argued that the difference was due to the higher mass diffusivity of helium causing the concentration of helium in the flame to be higher. However, Schug et al. [2] reported that argon is more efficient than helium in decreasing the tendency to soot when they were added to the fuel of a coflow ethylene diffusion flame. This result was attributed to helium's high thermal diffusivity and its subsequent influence on the temperature distribution. To sort out the relative influences of temperature and concentration modifications on the soot formation process, Axelbaum et al. [3] investigated the soot response to inert addition using counterflow diffusion flame. The result indicated that soot formation in diffusion flames could be significantly affected by concentration modification due to the preferential diffusion of the inert additives. By further examining the experimental results of Refs. $[2,4,5]$, Glassman [6] showed that for soot formation process in a diffusion flame, the dilution effects of added inerts should override the induced temperature effect.

Almost all the previous studies on the influences of inert additives on soot formation were conducted by experimental methods. The objective of the present paper is to present the results of a mathematical investigation of the relative influences of temperature and concentration modifications when inert diluents are added to fuel or oxidant in a coflow axisymmetric ethylene/air diffusion flame. Argon and helium are respectively used as the inert diluents to 
be added to fuel or oxidant. These gases are selected due to the substantially greater thermal and mass diffusivities of helium with respect to argon, while having the same specific heat.

\section{Numerical Methods}

The flame configuration studied is a coflow axisymmetric laminar ethylene/air diffusion flame [5]. The flames were generated with a burner in which the fuel (ethylene) flows from a $10.9 \mathrm{~mm}$ i.d. vertical tube, and the oxidant (air) flows from the annular region between the fuel tube and a $100 \mathrm{~mm}$ diameter concentric tube. The wall thickness of the fuel tube is $0.95 \mathrm{~mm}$.

\section{Governing Equations and Soot Model}

We employed the primitive variable method in which the fully elliptic governing equations were solved with detailed gas-phase chemistry and complex thermal and transport properties. Radiative heat transfer was calculated by the discrete ordinate method coupled to a statistical narrow-band correlated-k (SNBCK)-based wide-band model for the properties of $\mathrm{CO}, \mathrm{CO}_{2}, \mathrm{H}_{2} \mathrm{O}$, and soot [7]. The effects of soot inception, growth, and oxidation on gasphase chemistry were considered. The governing equations have been described elsewhere [8]. For the sake of brevity, only the model of soot formation, growth, and oxidation process is given here.

Two transport equations were solved for soot mass fraction and number density, respectively. They are

$$
\begin{aligned}
\rho v \frac{\partial Y_{\mathrm{s}}}{\partial r}+\rho u \frac{\partial Y_{\mathrm{s}}}{\partial z}= & -\frac{1}{r} \frac{\partial}{\partial r}\left(r \rho V_{\mathrm{T}, r} Y_{\mathrm{s}}\right) \\
& -\frac{\partial}{\partial z}\left(\rho V_{\mathrm{T}, z} Y_{\mathrm{s}}\right)+S_{\mathrm{m}} \\
\rho v \frac{\partial N}{\partial r}+\rho u \frac{\partial N}{\partial z}= & -\frac{1}{r} \frac{\partial}{\partial r}\left(r \rho V_{\mathrm{T}, r} N\right) \\
& -\frac{\partial}{\partial z}\left(\rho V_{\mathrm{T}, z} N\right)+S_{\mathrm{N}}
\end{aligned}
$$

where $Y_{\mathrm{S}}$ is the soot mass fraction, $N$ is the soot number density defined as the particle number per unit mass of mixture, $\rho$ is the density of the mixture, and $u$ and $v$ are the velocities in axial $(z)$ and radial $(r)$ directions, respectively. Quantities $V_{\mathrm{T}, r}$ and $V_{\mathrm{T}, z}$ are the particle thermophoretic velocities in $r$ (radial) and $z$ (axial) directions, respectively. They were obtained by the expression [9]

$$
V_{\mathrm{T}, x_{i}}=-0.55 \frac{\mu}{\rho T} \frac{\partial T}{\partial x_{i}} \quad x_{i}=r, z
$$

where $\mu$ is the viscosity of the mixture, and $T$ is the temperature of the mixture.
The source term $S_{\mathrm{m}}$ in equation 1 accounts for the contributions of soot nucleation $\left(\omega_{\mathrm{n}}\right)$, surface growth $\left(\omega_{\mathrm{g}}\right)$, and oxidation $\left(\omega_{\mathrm{o}}\right)$. Therefore,

$$
S_{\mathrm{m}}=\omega_{\mathrm{n}}+\omega_{\mathrm{g}}-\omega_{\mathrm{o}}
$$

The model developed by Leung et al. [9] and Fairwhether et al. [10] was used to obtain the three terms on the right-hand side of equation 4 . The model assumes the chemical reactions for nucleation and surface growth, respectively, as

$$
\begin{aligned}
\mathrm{C}_{2} \mathrm{H}_{2} & \rightarrow 2 \mathrm{C}(\mathrm{S})+\mathrm{H}_{2} \\
\mathrm{C}_{2} \mathrm{H}_{2}+n \mathrm{C}(\mathrm{S}) & \rightarrow(n+2) \mathrm{C}(\mathrm{S})+\mathrm{H}_{2}
\end{aligned}
$$

with the reaction rates given as

$$
\begin{gathered}
r_{1}=k_{1}(T)\left[\mathrm{C}_{2} \mathrm{H}_{2}\right] \\
r_{2}=k_{2}(T) f\left(A_{\mathrm{s}}\right)\left[\mathrm{C}_{2} \mathrm{H}_{2}\right]
\end{gathered}
$$

where $f\left(A_{\mathrm{s}}\right)$ denotes the functional dependence on soot surface area per unit volume. In the present paper, the simplest, linear functional dependence was used; that is, $f\left(A_{\mathrm{s}}\right)=A_{\mathrm{s}}$.

Neoh et al. [11] investigated the soot oxidation process in flames and found that the oxidation due to both $\mathrm{O}_{2}$ and $\mathrm{OH}$ is important, depending on the local equivalence ratio. The radical $\mathrm{O}$ also contributes to soot oxidation in some regions. Therefore $\mathrm{O}_{2}$, $\mathrm{OH}$, and $\mathrm{O}$ were assumed to participate in the following reactions:

$$
\begin{gathered}
0.5 \mathrm{O}_{2}+\mathrm{C}(\mathrm{S}) \rightarrow \mathrm{CO} \\
\mathrm{OH}+\mathrm{C}(\mathrm{S}) \rightarrow \mathrm{CO}+\mathrm{H} \\
\mathrm{O}+\mathrm{C}(\mathrm{S}) \rightarrow \mathrm{CO}
\end{gathered}
$$

The reaction rates for these three reactions were obtained from the expressions

$$
\begin{gathered}
r_{3}=k_{3}(T) T^{1 / 2} A_{\mathrm{s}}\left[\mathrm{O}_{2}\right] \\
r_{4}=\varphi_{\mathrm{OH}} k_{4}(T) T^{-1 / 2} A_{\mathrm{s}} X_{\mathrm{OH}} \\
r_{5}=\varphi_{\mathrm{O}} k_{5}(T) T^{-1 / 2} A_{\mathrm{s}} X_{\mathrm{o}}
\end{gathered}
$$

where $X_{\mathrm{OH}}$ and $X_{\mathrm{O}}$ denote the mole fractions of $\mathrm{OH}$ and $\mathrm{O}$, and $\varphi_{\mathrm{OH}}$ and $\varphi_{\mathrm{O}}$ are the collision efficiencies for $\mathrm{OH}$ and $\mathrm{O}$ attack on soot particles. The collision efficiency of $\mathrm{OH}$ was treated as that described by Kennedy et al. [12], who accounted for the variation of the collision efficiency of $\mathrm{OH}$ with time by assuming a linear relation between the collision efficiency and a dimensionless distance from the fuel nozzle exit. A collision efficiency of 0.5 for radical $\mathrm{O}$ attack on the particles was used [13].

All the reaction rate constants, $k_{\mathrm{i}}(i=1, \ldots, 5)$, are given in Table 1.

The source term $S_{\mathrm{N}}$ in equation 2 accounts for the soot nucleation and agglomeration and was calculated as 
TABLE 1

Rate constants, as $A \exp (-E / R T)^{1}$

\begin{tabular}{lcrl}
\hline$k_{i}$ & $A$ & $E$ & Ref. \\
\hline$k_{1}$ & $1.35 \mathrm{E}+06$ & 41 & {$[10]$} \\
$k_{2}$ & $5.00 \mathrm{E}+02$ & 24 & {$[10]$} \\
$k_{3}$ & $1.78 \mathrm{E}+04$ & 39 & {$[10]$} \\
$k_{4}$ & $1.06 \mathrm{E}+02$ & 0 & {$[11]$} \\
$k_{5}$ & $5.54 \mathrm{E}+01$ & 0 & {$[13]$} \\
\hline
\end{tabular}

${ }^{1}$ Units are $\mathrm{kg}, \mathrm{m}, \mathrm{s}$, kcal, kmol, and $\mathrm{K}$.

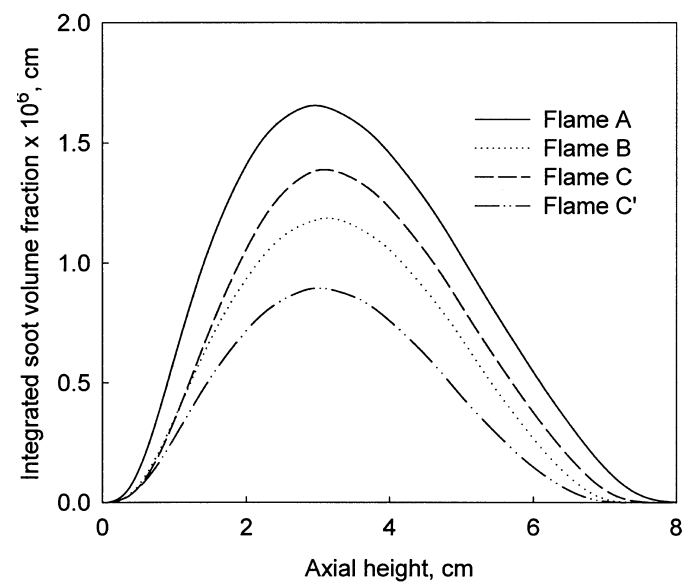

FIG. 1. Effect of diluent addition to the fuel on the integrated soot volume fraction.

$$
\begin{aligned}
S_{\mathrm{N}}= & \frac{2}{C_{\min }} N_{\mathrm{A}} r_{1}-2 C_{\mathrm{a}}\left(\frac{6 M_{\mathrm{C}(\mathrm{S})}}{\pi \rho_{\mathrm{C}(\mathrm{S})}}\right)^{1 / 6}\left(\frac{6 \kappa T}{\rho_{\mathrm{C}(\mathrm{S})}}\right)^{1 / 2} \\
& \times[\mathrm{C}(\mathrm{s})]^{1 / 6}[\rho N]^{11 / 6}
\end{aligned}
$$

where $N_{\mathrm{A}}$ is Avogadro's number (6.022 $\times 10^{26}$ particles $/ \mathrm{kmol}$ ), $C_{\min }$ is the number of carbon atoms in the incipient carbon particle $\left(9 \times 10^{4}\right)[10], \kappa$ is the Boltzmann constant $\left(1.38 \times 10^{-23} \mathrm{~J} / \mathrm{K}\right), \rho_{\mathrm{C}(\mathrm{S})}$ is the soot density $\left(1800 \mathrm{~kg} / \mathrm{m}^{3}\right),[C(s)]$ is the mole concentration of soot $\left(\mathrm{kmol} / \mathrm{m}^{3}\right), M_{\mathrm{C}(\mathrm{s})}$ is the molar mass of soot $(12.011 \mathrm{~kg} / \mathrm{kmol})$, and $C_{\mathrm{a}}$ is the agglomeration rate constant for which a value of 3.0 [10] was used.

\section{Numerical Model}

The governing equations were discretized using the control volume method. The SIMPLE numerical scheme [14] was used to deal with the pressure and velocity coupling. The diffusion and convective terms in the conservation equations were respectively discretized by the central and upwind difference methods. The discretized equations of gas species, soot mass fraction, and soot number density were solved in a fully coupled fashion on every grid to speed up the convergence process [15], while those of momentum, energy, and pressure correction were solved using the tridiagonal matrix algorithm.

The computational domain covers an area from 0 to $3.0 \mathrm{~cm}$ in the radial direction and 0 to $11.0 \mathrm{~cm}$ in the axial direction. The inflow boundary $(z=0 \mathrm{~cm})$ corresponds to the region immediately above the fuel nozzle. The fuel used in the present study is ethylene. Argon and helium were used as diluents added to fuel or oxidant of the flame.

The chemical reaction mechanism used is essentially from GRI-MECH 3.0 [16], with the removal of all the reactions and species related to $\mathrm{NO}_{x}$ formation. All the thermal and transport properties were obtained by using the database of GRI-MECH 3.0 and the algorithms given in Refs. $[17,18]$.

\section{Results and Discussion}

The simulations were conducted for both options: adding diluents to fuel and to oxidant streams. Five flames were studied. They are: flame A-pure ethylene/air flame; flame B-with $30 \%$ argon (mole base) added to the fuel of flame A; flame $\mathrm{C}$-with $30 \%$ helium (mole base) added to the fuel of flame A; flame D-with 30\% argon (mole base) added to the air of flame A; and flame E-with $30 \%$ helium (mole base) added to the air of flame A. In addition, three fictitious flames were simulated to identify the relative influence of temperature and concentration modifications. They are: flame $\mathrm{C}^{\prime}$ - with the same gas compositions as for flame $\mathrm{C}$, but the same temperatures as for flame $\mathrm{B}$; flame $\mathrm{E}^{\prime}$ —with the same gas compositions as for flame $\mathrm{E}$, but the same temperatures as for flame D; and flame $\mathrm{E}^{\prime \prime}$ - with the same inlet boundary conditions as for flame $\mathrm{E}$, but the same temperatures as for flame D. In all the flames, the mass flow rates of fuel and air are the same, while the diluents were added to either the fuel or the air stream of flames B-E".

\section{Adding Diluents to Fuel}

Shown in Fig. 1 are the integrated soot volume fractions, obtained by integrating soot volume fraction with respect to radius, for four flames. It illustrates that argon is more efficient at suppressing soot formation than helium when it is added to the fuel of an ethylene/air diffusion flame. This is qualitatively consistent with the experimental result of Schug et al. [2]. Since argon and helium are chemically inert and have the same specific heat, the difference in their effects on soot formation must be a consequence of the different transport properties. Curve $\mathrm{C}^{\prime}$, constructed to show the relative influence of temperature and concentration changes, will be 

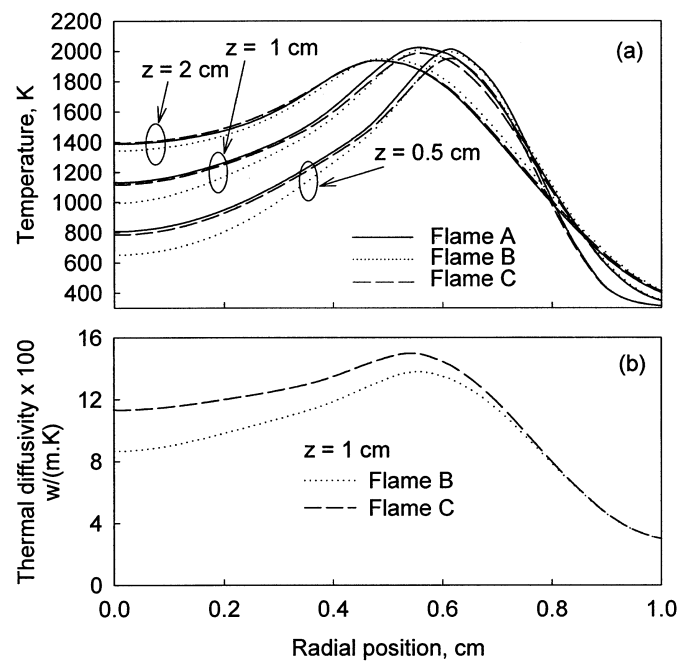

FIG. 2. Radial flame temperature profiles of flames A, $\mathrm{B}$, and $\mathrm{C}$ at three different axial heights and the thermal diffusivities of flames $\mathrm{B}$ and $\mathrm{C}$ at the axial height of $z=$ $1 \mathrm{~cm}$.

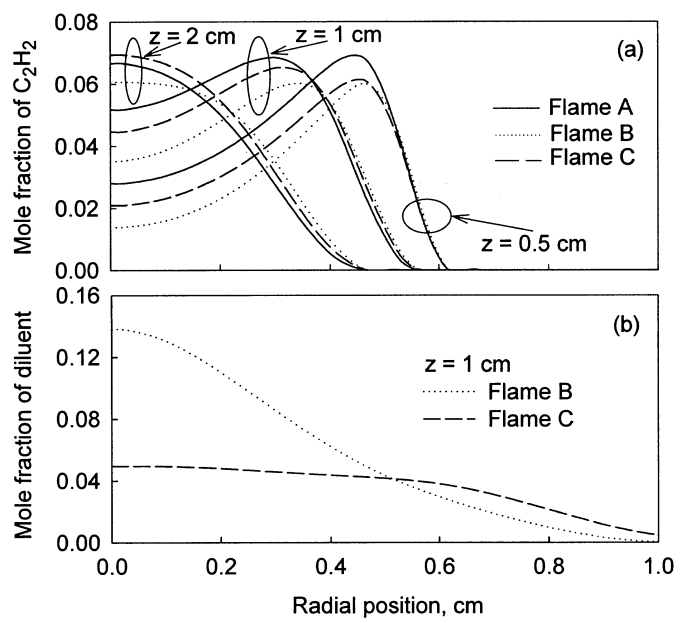

FIG. 3. Acetylene mole fraction profiles of flames A, B, and $\mathrm{C}$ at three axial heights and the diluent concentrations of flames B and C at the axial height of $z=1 \mathrm{~cm}$.

discussed in a later section. As soot inception and surface growth occur predominantly below $z=$ $3 \mathrm{~cm}$, results are shown for only the lower regions of the flame.

Although the simulations indicate that the difference in the maximum flame temperature between flames $\mathrm{B}$ and $\mathrm{C}$ is only $26 \mathrm{~K}$, the temperature distributions are different for the two flames, as shown in Fig. 2a. The higher thermal diffusivity of helium results in higher temperatures in the centerline region for flame $\mathrm{C}$ than for flame B. Fig. $2 \mathrm{~b}$ illustrates

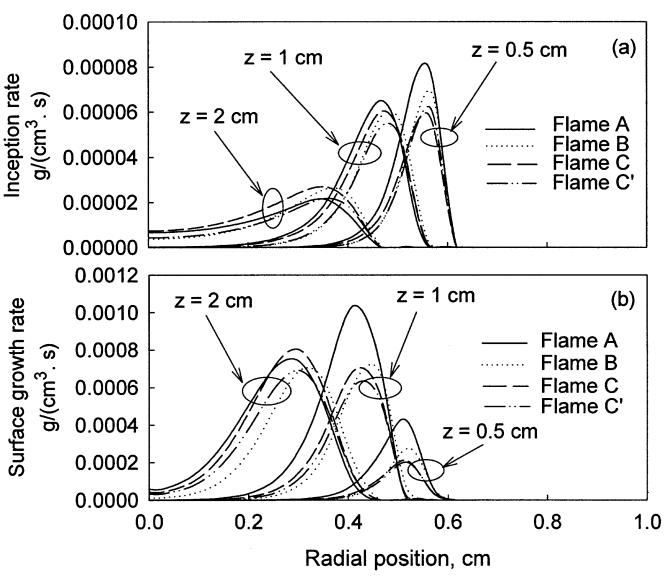

FIG. 4. Particle inception and surface growth rates at three different axial heights.

that the thermal diffusivity of flame $\mathrm{C}$ is significantly higher than that of flame $\mathrm{B}$ in the centerline region. As a result, the maximum temperature of flame $\mathrm{C}$ is a little lower than that of flame $\mathrm{B}$, since more reaction heat in flame $\mathrm{C}$ is conducted away from the primary (annular) reaction zone.

Similar to the temperature distribution, the higher mobility of helium results in higher concentrations of acetylene in the centerline region for flame $\mathrm{C}$ than for flame B, as shown in Fig. 3a. However, with the increase of radial distance from the centerline, the differences of acetylene concentration between flames B and C gradually decrease, and finally the acetylene concentrations of flame $\mathrm{C}$ become lower than those of flame B. This is because helium diffuses more rapidly toward the periphery than argon. As demonstrated in Fig. 3b, the argon concentration of flame $\mathrm{B}$ is much higher than the helium concentration of flame $\mathrm{C}$ in the centerline region, and the situation reverses at the periphery.

The above temperature and acetylene concentration differences between flames B and $\mathrm{C}$ result in different soot particle inception and surface growth processes, as shown in Fig. 4. Since both inception and surface growth rates depend on the temperature and acetylene concentration, the maximum rates of inception and growth occur in the annular region between the peak flame temperature and peak acetylene concentration locations.

At the lowest axial height $(z=0.5 \mathrm{~cm})$, the inception rates of flame $\mathrm{C}$ are actually lower than those of flame B in the region between the locations of peak acetylene concentration and peak temperature, owing to the higher acetylene concentrations of flame $\mathrm{B}$. Although the acetylene concentrations of flame $\mathrm{C}$ in the centerline region are higher, the temperatures are too low for inception. Similarly, the surface growth rates of flame $\mathrm{B}$ are higher than those of 


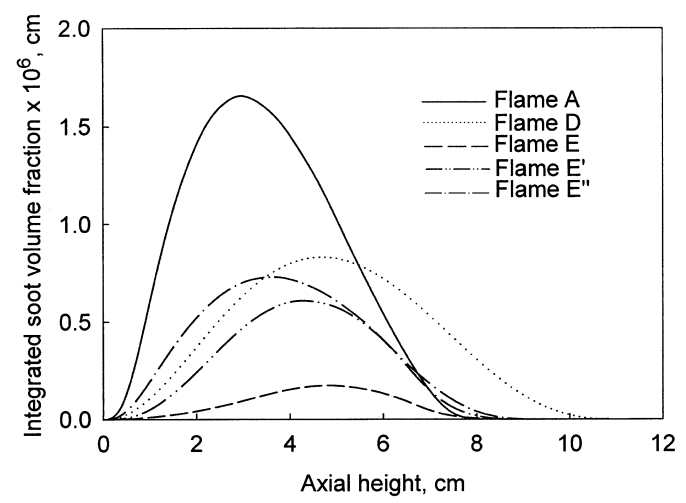

FIG. 5. Effect of diluent addition to the air on integrated soot volume fraction.

flame $\mathrm{C}$ in the region between the peak acetylene concentration and peak temperature positions when axial height equals $0.5 \mathrm{~cm}$. The peak surface growth rate is closer to the axis than the peak inception rate because of the lower activation energy.

With the increase of axial height to $z=1 \mathrm{~cm}$, the peak inception rates of flames $\mathrm{B}$ and $\mathrm{C}$ become similar. Although the acetylene concentrations of flame $\mathrm{C}$ are still lower than those of flame $\mathrm{B}$ in the region where the peak inception rates are located, the temperatures of flame $\mathrm{C}$ are higher than those of flame $\mathrm{B}$, and this is the dominant effect. In the region inside the peak inception rate location, both higher temperatures and higher acetylene concentrations contribute to higher inception rates for flame C. A similar situation can be found for the surface growth process.

When the axial height is further increased to $z=$ $2 \mathrm{~cm}$, the peak inception rate of flame $\mathrm{C}$ has further increased relative to flame $\mathrm{B}$, because of the higher temperatures of flame $\mathrm{C}$ in the region where the peak inception rates are located. In the centerline region, the inception rates of both flames $\mathrm{B}$ and $\mathrm{C}$ become significant, and those of flame $\mathrm{C}$ are much higher than those of flame B. This is because the peak acetylene concentration locations of all flames have shifted toward the centerline, and the temperatures in the centerline region have risen to levels high enough to stimulate significant inception. For surface growth, although the situation is similar to inception, the peak surface growth rate of flame $\mathrm{C}$ significantly surpasses that of flame $\mathrm{B}$. The reason is that the surface growth process depends on not only the local temperature and acetylene concentration but also the particle surface area, which is closely related to the local and upstream inception processes.

The above results show that the shift toward higher inception and surface growth rates of flame $\mathrm{C}$ at most locations except the lowest axial height $(z=0.5 \mathrm{~cm})$ is due to the higher temperatures of flame $\mathrm{C}$ in the peak inception and surface growth regions. As clearly shown in Fig. 4, the inception and surface growth rates of the fictitious flame $\mathrm{C}^{\prime}$ are lower than those of flames B and $\mathrm{C}$ at most locations. The differences between flames B and $\mathrm{C}^{\prime}$ are caused only by the concentration differences, and those between flames $\mathrm{C}$ and $\mathrm{C}^{\prime}$ are caused by temperature modification.

Although at lower axial height $(z=0.5 \mathrm{~cm})$, both inception and surface growth rates of flame $\mathrm{C}$ are less than those of flame B, the differences gradually diminish with the increase of axial height, and the situation reverses at higher axial height. Especially the surface growth rate is about 1 order of magnitude greater than the inception rate, and the surface growth rates above $z=0.5 \mathrm{~cm}$ are much higher than those at $z=0.5 \mathrm{~cm}$. Therefore, most soot mass in these flames is formed by the surface growth process. As shown in Fig. 1, if the temperature differences are removed, the integrated soot volume fractions of flame $\mathrm{C}^{\prime}$ are lower than those of flame B due to the effect of acetylene concentration.

We can conclude that when argon or helium is added to the fuel, their respective effects on the soot yields in the flames vary, due to modified temperature and acetylene concentration distributions, caused by the differences in thermal and mass diffusivities. Temperature modification is the dominant effect, causing greater soot suppression with argon addition than with helium addition to the fuel stream.

\section{Adding Diluents to Air}

Figure 5 shows the integrated soot volume fractions for flames A, D, E, E', and $\mathrm{E}^{\prime \prime}$. It is clear when the diluent is added to the air stream, the effects of helium and argon are reversed from the effects when they are added to the fuel stream. As before, this is owing to the different thermal and mass diffusivities of the diluents. The results of flames $\mathrm{E}^{\prime}$ and $\mathrm{E}^{\prime \prime}$ will be discussed later.

Shown in Fig. 6 are the temperature distributions along the radial direction at two different axial heights. The simulations indicate that the maximum temperatures of flames A, D, and E are 2029, 1862 , and $1596 \mathrm{~K}$, respectively. The higher thermal diffusivity of helium causes a broader temperature distribution but lower peak flame temperature along the radial direction for flame $\mathrm{E}$ than for flame $\mathrm{D}$.

A similar situation can be found for the distributions of acetylene concentration, as shown in Fig. 7. The acetylene concentrations of flame $\mathrm{E}$ are much lower than for flame D except at the periphery, because helium has a higher diffusivity than argon.

The inception and surface growth rate distributions for flames A, D, and E are shown in Fig. 8 for 


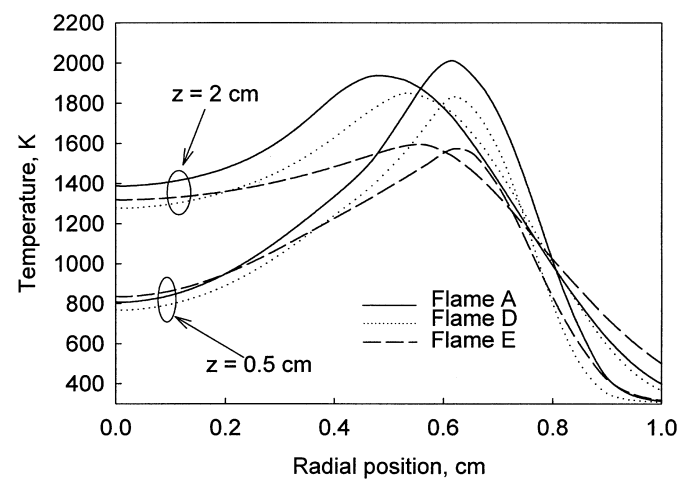

FIG. 6. Flame temperature distributions at two different axial heights.

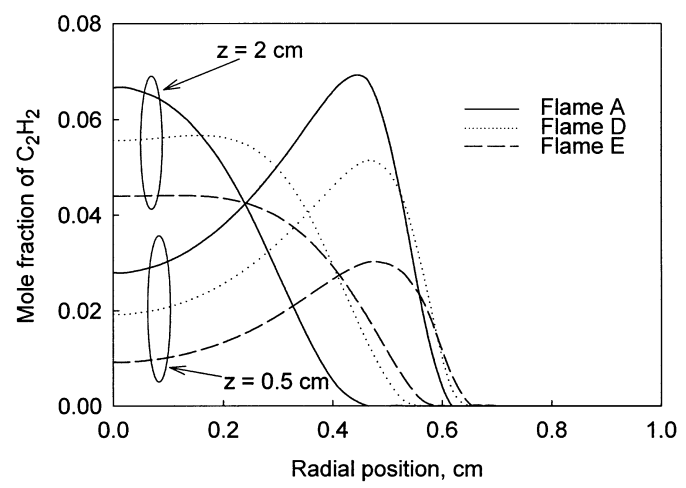

FIG. 7. Acetylene mole fraction distributions at two axial heights.

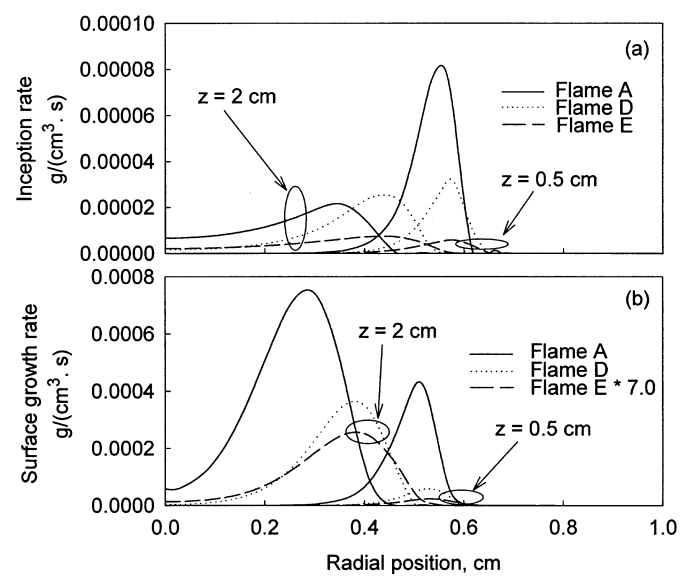

FIG. 8. Particle inception and surface growth rates at two axial heights. two different axial heights. Since both acetylene concentrations and temperatures of flame $\mathrm{E}$ are lower than those of flame D in most of the inception and surface growth region, the rates of flame $\mathrm{E}$ are much lower than those of flame D. Therefore, both temperature and concentration modifications are responsible for the lower soot yield of flame E than that of flame D.

To determine which effect is relatively more important for the reduction of soot inception and surface growth rates, the integrated soot volume fractions of the fictitious flame $\mathrm{E}^{\prime}$ are shown in Fig. 5. The differences in soot volume fraction between flames $\mathrm{D}$ and $\mathrm{E}^{\prime}$ are caused only by the concentration differences, and those between flames $\mathrm{E}$ and $\mathrm{E}^{\prime}$ are caused by temperature modification. Fig. 5 illustrates that the differences of integrated soot volume fractions between flames $\mathrm{D}$ and $\mathrm{E}^{\prime}$ are smaller than those between flames $\mathrm{E}$ and $\mathrm{E}^{\prime}$. This implies the temperature modification is relatively more important.

Moreover, the temperature modification itself also causes a concentration modification due to the variation of mass diffusivity with temperature, which in turn causes more variation in the soot yield. As shown in Fig. 5, if we resimulate flame E by keeping its temperatures as the same as for flame D, the integrated soot volume fractions of this flame (flame $\left.\mathrm{E}^{\prime \prime}\right)$ are higher than those of flame $\mathrm{E}^{\prime}$. Thus, the variations of diffusivities with temperature give rise to the significance of the temperature effect.

\section{Conclusions}

The results of numerical simulation of laminar ethylene/air flames with helium and argon added to the fuel alone and to the air alone show that the differences in effects of argon and helium addition on soot formation process are a consequence of the disparities in the transport properties. When the diluents are added to the fuel stream, it is the temperature difference caused by the different thermal diffusivities that causes argon to be more efficient at suppressing soot formation than helium. However, when they are added to the coflow air, although both temperature and concentration modifications cause helium to be more efficient at suppressing soot formation than argon, it is the temperature modification that is more significant.

\section{REFERENCES}

1. McLintock, I. S., Combust. Flame 12:217 (1968).

2. Schug, K. P., Manheimer-Timnat, Y., Yaccarino, P., and Glassman, I., Combust. Sci. Technol. 22:235 (1980).

3. Axelbaum, R. L., Law, C. K., and Flower, W. L., Proc. Combust. Inst. 22:379 (1988). 
4. Axelbaum, R. L., and Law, C. K., Proc. Combust. Inst. 23:1517 (1990).

5. Gülder, Ö. L., Snelling, D. R., and Sawchuk, R. A., Proc. Combust. Inst. 26:2351 (1996).

6. Glassman, I., Proc. Combust. Inst. 27:1589 (1998).

7. Liu, F., Smallwood, G. J., and Gülder, Ö. L., AIAA paper 99-3679.

8. Guo, H., Liu, F., Smallwood, G., and Gülder, Ö. L., Combust. Theory Modelling 6:173 (2002).

9. Leung, K. M., Lindstedt, R. P., and Jones, W. P., Combust. Flame 87:289 (1991).

10. Fairwhether, M., Jones, W. P., and Lindstedt, R. P., Combust. Flame 89:45 (1992).

11. Neoh, K. G., Howard, J. B., and Sarofim, A. F., in Particulate Carbon: Formation During Combustion (D. C. Siegla and G. W. Smith, eds.), Plenum Press, New York, 1981, p. 261.
12. Kennedy, I. M., Yam, C., Rapp, D. C., and Santoro, R. J., Combust. Flame 107:368 (1996).

13. Bradley, D., Dixon-Lewis, G., Habik, S. E., and Mushi, E. M., Proc. Combust. Inst. 20:931 (1984).

14. Patankar, S. V., Numerical Heat Transfer and Fluid Flow, Hemisphere, New York, 1980.

15. Liu, Z., Liao, C., Liu, C., and McCormick, S., AIAA paper 95-0205.

16. Smith, G. P., Golden, D. M., Frenklach, M., Moriarty, N. W., Eiteneer, B., Goldenberg, M., Bowman, C. T., Hanson, R. K., Song, S., Gardiner Jr., W. C., Lissianski, V. V., and Qin, Z., University of California, Berkeley, 1999, www.me.berkeley.edu/gri_mech/.

17. Kee, R. J., Miller, J. A., and Jefferson, T. H., Sandia report SAND 80-8003.

18. Kee, R. J., Warnatz, J., and Miller, J. A., Sandia report SAND 83-8209.

\section{COMMENTS}

Mitchell Smooke, Yale University, USA. What technique was used to measure the soot? In addition, do you have experimental and numerical comparisons for any of the diluted flames? Moreover, did the computations for the diluted flames show a migration of the soot from the flame wings to the flame centerline?

Author's Reply. The soot in pure ethylene/air diffusion flame was measured by the transmission of an Ar-ion (514.5 $\mathrm{nm}$ ) laser beam (Ref. [5] in paper). Although we don't have the direct comparisons between the numerical and experimental results for the diluted flames, the conclusions from the present paper are qualitatively consistent with those existing experimental results, as indicated in the paper. The computations did not show any migration of the soot from the flame wings to the centerline for the diluted flames.
Hai Wang, University of Delaware, USA. Have you examined the effect of diluent on the $\mathrm{H}$ atom concentration in the flame, and how does the variation of the $\mathrm{H}$ atom concentration affect soot formation?

Author's Reply. The addition of both helium and argon reduces the $\mathrm{H}$ atom concentration in the flames. The variation of the $\mathrm{H}$ atom concentration may affect (decrease) the soot formation to some extent. However, this should not affect the conclusion of this paper, since the reduction of the $\mathrm{H}$ atom concentration is mainly a result of the flame temperature decrease. 